\title{
Climate Change Science Facts
}

\section{Climate change is}

a real and urgent

challenge that is already

affecting people and the

environment worldwide.

Significant changes are

occurring on Earth,

including increasing air

and ocean temperatures,

widespread melting of

snow and ice, and rising

sea levels. This fact sheet

discusses key scientific

facts that explain the

causes and effects of

climate change today,

as well as projections for

the future.

\section{Causes of Climate Change}

Climate change is a term that refers to major changes in temperature, rainfall, snow, or wind patterns lasting for decades or longer. Both human-made and natural factors contribute to climate change:

- Human causes include burning fossil fuels, cutting down forests, and developing land for farms, cities, and roads. These activities all release greenhouse gases into the atmosphere.

- Natural causes include changes in the Earth's orbit, the sun's intensity, the circulation of the ocean and the atmosphere, and volcanic activity.

Although the Earth's climate has changed many times throughout its history, the rapid warming seen today cannot be explained by natural processes alone.

Human activities are increasing the amount of greenhouse gases in the atmosphere. Some amount of greenhouse gases is necessary for life to exist on Earth-they trap heat in the atmosphere, keeping the planet warm and in a state of equilibrium. But this natural greenhouse effect is being strengthened as human activities (such as the combustion of
Heat-trapping greenhouse gases are now at record-high levels in the atmosphere compared with the recent and distant past. fossil fuels) add more of these gases to the atmosphere, resulting in a shift in the Earth's equilibrium.

\section{The Link Between Greenhouse Gases and Temperature, 1850-2009}

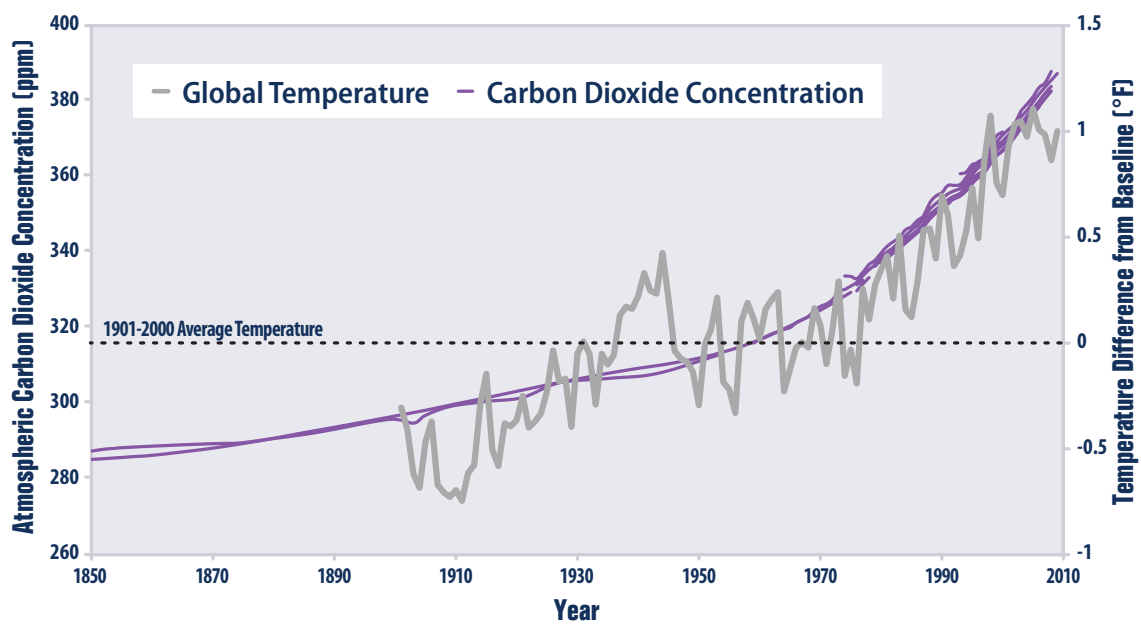

Source: Carbon Dioxide Information Analysis Center. 20I0. http://cdiac.ornl.gov/ and National Oceanic and Atmospheric Administration. 2010. www.noaa.gov

Emissions of carbon dioxide, an important greenhouse gas, have been increasing since the Industrial Revolution. These emissions are causing carbon dioxide levels to build up in the atmosphere and global temperatures to rise. In particular, temperatures have gone up at an increased rate over the past 30 years. Carbon dioxide data in this figure are compiled from several different studies. Temperature data show the difference from the average or baseline temperature between 1901 and 2000. 


\section{As the climate}

continues to warm, more changes are

expected to occur

and many effects

will become more

pronounced over

time.

\section{Signs of Climate Change}

Climate change is happening now, and the effects can be seen on every continent and in every ocean. While certain effects of climate change can be beneficial, particularly in the short term, current and future effects of climate change pose considerable risks to people's health and welfare, and the environment.

There is now clear evidence that the Earth's climate is warming:

- Global surface temperatures have risen by 1.3 degrees Fahrenheit ( ${ }^{\circ} \mathrm{F}$ ) over the last 100 years.

- Worldwide, the last decade has been the warmest on record.

- The rate of warming across the globe over the last 50 years $\left(0.24^{\circ} \mathrm{F}\right.$ per decade) is almost double the rate of warming over the last 100 years $\left(0.13^{\circ} \mathrm{F}\right.$ per decade).

The evidence of climate change extends well beyond increases in global surface temperatures. It also includes:

- Changing precipitation patterns.

- Melting ice in the Arctic.

- Melting glaciers around the world.

- Increasing ocean temperatures.

- Rising sea level around the world.

- Acidification of the oceans due to elevated carbon dioxide in the atmosphere.

- Responses by plants and animals, such as shifting ranges.

\section{Temperatures in the Lower 48 States, 1901-2009}

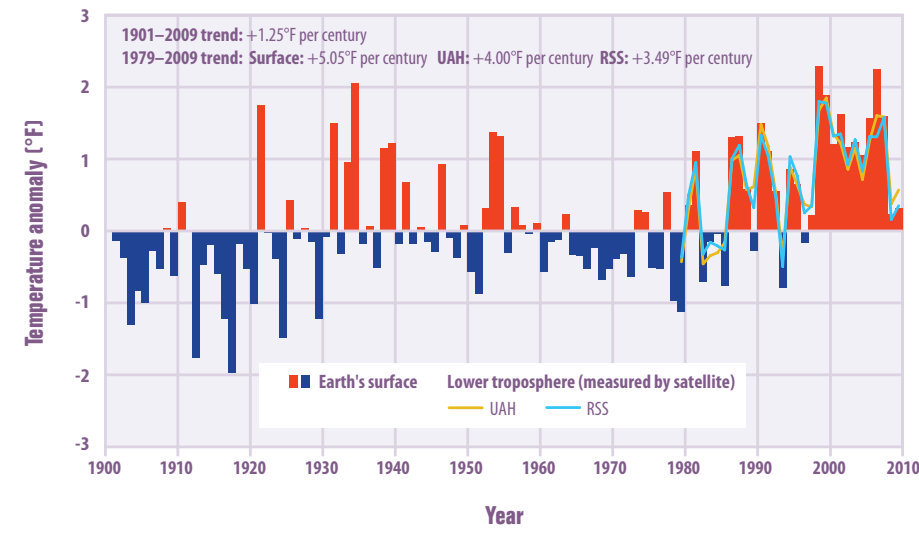

Source: National Oceanic and Atmospheric Administration. 2010 www.ncdc.noaa.gov/oa/ncdc.html

Since 1901, temperatures have risen across the lower 48 states at an average rate of $0.13^{\circ} \mathrm{F}$ per decade $\left(1.3^{\circ} \mathrm{F}\right.$ per century). Average temperatures have risen more quickly since the late 1970 s.

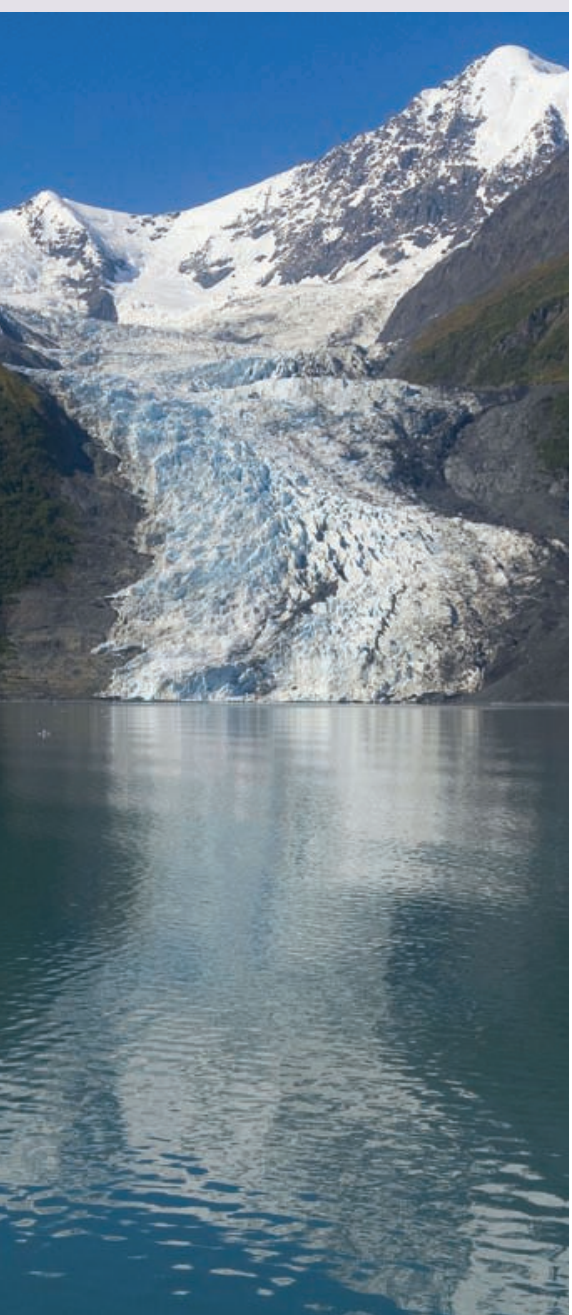

\section{Projections of Climate Change}

At the current rate, the Earth's global average temperature is projected to rise from 3 to $7^{\circ} \mathrm{F}$ by 2100, and it will get even warmer after that. As the climate continues to warm, more changes are expected to occur, and many effects will become more pronounced over time. For example, heat waves are expected to become more common, severe, and longer lasting. Some storms are likely to become stronger and more frequent, increasing the chances of flooding and damage in coastal communities.

Climate change will affect different regions, ecosystems, and sectors of the economy in many ways, depending not only on the sensitivity of those systems to climate change, but also on their ability to adapt to risks and changing conditions. Throughout history, societies and ecosystems alike have shown remarkable capacity to respond to risks and adapt to different climates and environmental changes. Today, effects of climate change have already been observed, and the rate of warming has increased in recent decades.

For this reason, human-caused climate change represents a serious challenge-one that could require new approaches and ways of thinking to ensure the continued health, welfare, and productivity of society and the natural environment.

\section{For More Information}

For detailed information about greenhouse gas emissions, the effects of climate change, EPA efforts underway, and tips on what you can do, visit EPA's Climate Change Web site at www.epa.gov/climatechange. 